\title{
Production des acides gras libres par des bactéries de la fermentation lactique et des moisissures sur le milieu de caséine
}

\author{
par \\ J. KOWALEWSKA, S. POZNANSKI et J. JAWORSKI \\ Institut du Génie et de la Biotechnologie Alimentaire, \\ Université d'Agriculture, Olsztyn (Pologne) \\ Directeur de l'Institut : Professeur agrégé Dr habil. S. POZNANSKI
}

\section{Introduction}

Les caractéristiques de qualité des fromages affinés sont liées strictement avec la qualité et la quantité des produits de transformation (métabolisme) des hydrates de carbone, des protéines et des lipides.

Dans le procédé d'affinage des diverses sortes de fromages, prennent part des combinaisons caractéristiques des enzymes qui sont produites par des micro-organismes et qui conditionnent la tendance désirée des transformations. C'est pourquoi le choix des combinaisons convenables de souches de bactéries lactiques ou de moisissures, qui entrent dans la composition des levains de fromagerie, joue un rôle très important et demeure toujours actuel.

Parmi les produits de métabolisme qui se fermentent au cours de l'affinage du fromage, et qui exercent une influence directe sur le développement de l'odeur et de la saveur du produit fini, on trouve entre autres des acides gras libres de poids moléculaire bas. Des recherches des dernières années ont démontré que la proportion qualitative et quantitative des acides gras libres à courte chaîne dans des fromages affinés est liée généralement à des transformations des protéines. Nakae et Elliot [4-5] ont rapporté que des acides gras de $\mathrm{C}_{2}$ à $\mathrm{C}_{6}$ étaient produits par des bactéries de la fermentation lactique à partir d'hydrolysats de caséine, de certains acides aminés et de leurs mélanges. Dans la gamme des acides produits, c'était l'acide acétique qui avait la part essentielle et beaucoup d'investigateurs lui attribuaient une influence favorable sur les propriétés de saveur et d'odeur des fromages affinés [7-8]. Nikit Yoshioka et Ahikok [6] qui étudiaient l'activité lipolytique des souches diverses de $P$. roqueforti, ont constaté qu'une souche douée d'activité pro- 
téolytique plus élevée produisait sensiblement plus d'acide acétique que d'acide butyrique et caproïque. Une activité tout à fait contraire a été constatée dans le cas d'une souche ayant une activité lipolytique élevée. D'après Efthymion [1], des fromages à saveur douce contenaient plus d'acide acétique que des fromages à saveur défectueuse. Harper et Long [2] ont signalé un certain rapport entre la teneur en acide butyrique et en acides gras supérieurs à l'intensité de la saveur et de l'odeur du fromage. Zegarska a démontré qu'une relation existait entre la quantité et la qualité des acides gras libres à courte chaîne, d'une part, et la qualité du fromage, de l'autre. Des acides gras libres provenant de l'hydrolyse de la matière grasse n'influençaient pas les caractéristiques de qualité. Nos recherches ont décelé des relations semblables.

L'investigation des aptitudes de produire des acides gras libres à partir de la caséine, chez certaines bactéries de la fermentation lactique et des moisissures nous paraît utile, étant donné que des suspensions de ces micro-organismes où des préparations enzymatiques pourraient être utilisées à l'avenir pour l'affinage des fromages.

\section{Expérimentation}

On a étudié l'aptitude à produire des acides gras libres, au cours de la décomposition de solutions tamponnées à 3 p. 100 de caséine pure, par des souches, des bactéries de la fermentation lactique et des moisissures suivantes : Str. lactis-T, Str. diacetilactis-157, Str. cremoris $-319, P$. roqueforti WR-16, Oidium lactis-15, Rhizopus CRS-33162 et Zygorhyntus Meelleri LECK-81. La caséine isoélectrique était obtenue à partir du lait frais d'après Ribadeau-Dumas [10]. Dissoute dans l'eau, la caséine était additionnée de $\mathrm{MgSO}_{ \pm}(0,05 \mathrm{p} .100)$ et de $\mathrm{K}_{2} \mathrm{HPO}_{+}(0,5 \mathrm{p}, 100)$. Puis la solution était ajustée à $\mathrm{pH} 6,5$ et 5,5 en y ajoutant $\mathrm{H}_{2} \mathrm{SO}_{4}$ avec agitation continuelle, puis pasteurisée à $0,4 \mathrm{~atm}$. pendant $10 \mathrm{mn}$.

\section{A) OBTENTION DES SUSPENSIONS DE GERMES MICROBIENS}

Les bactéries de la fermentation lactique étaient cultivées par le système stationnaire, le pH étant ajusté entre 5,9-6,5, sur le milieu qui avait été préparé d'après Valles et Mocquot [14]. L'acide lactique produit était neutralisé avec $5 \mathrm{n} \mathrm{NaOH}$, sous agitation continuelle de la culture. La culture terminée $(12-14 \mathrm{~h})$ les germes étaient centrifugés et lavés plusieurs fois avec la solution tampon de phosphate à pH 7 et la centrifugation était répétée.

B) CONDITIONS dE LA DÉCOMPOSITION DE LA CASÉINE PAR DES SUSPENSIONS DE GERMES

Une suspension de germes récemment centrifugés était ajoutée à la solution à 3 p. 100 de caséine à $\mathrm{pH} 6,5$ et 5,5 à raison de $5 \mathrm{mg}$ de germes $/ \mathrm{ml}$. Après incubation de $5 \mathrm{j}$, à la température de $25^{\circ} \mathrm{C}$ 
pour Str. lactis et pour Str. diacetilactis, et de $30^{\circ} \mathrm{C}$ pour Str. cremoris, on procédait à la séparation des acides gras libres.

c) Conditions de la dÉcomposition de la CASÉine PAR dES MOISISSURES

Des solutions stériles de caséine à 3 p. 100 ayant un $\mathrm{pH}$ de 5,5 étaient ensemencées avec 10 p. 100 d'une culture de moisissures. L'inoculum était préparé, lui aussi, sur la solution de caséine à 3 p. 100 (culture de $24 \mathrm{~h}$ ), en y ajoutant des cultures diverses de moisissures, développées sur gélose inclinée. En tout cas, l'incubation était effectuée à $25^{\circ} \mathrm{C}$ pendant $24 \mathrm{~h}$ et $5 \mathrm{j}$. Ce temps écoulé, les acides gras libres étaient séparés du milieu.

D) OBTENTION DES PRÉPARATIONS ENZYMATIQUES DE LA MOISISSURE Zygorhyntus Meelleri

La moisissure était cultivée dans la solution de D-glucose à 2 p. 100 additionnée de $\mathrm{MgSO}_{4}$ et de $\mathrm{K}_{2} \mathrm{HPO}_{4}$, dans des boîtes de Roux. Après 4 j, le milieu était filtré sur bougie de Chamberland. Le filtrat était condensé dans le vacum, à $25^{\circ} \mathrm{C}$, et les enzymes étaient précipitées avec de l'acétone (10 volumes d'acétone pour un volume de filtrat). Les enzymes précipitées étaient séparées par centrifugation puis ajoutées à la solution de caséine, comme ci-dessus (paragraphe c).

Les germes qui avaient été recueillis dans la bougie étaient broyés dans un "mixer » et ajoutés, eux aussi, aux solutions stériles de caséine. En tout cas, les acides gras étaient séparés après $5 \mathrm{j}$ d'incubation.

\section{Méthodes analytiques}

\section{A) Obtention des Savons et dosage des acides gRas Libres}

Les acides gras libres étaient séparés de la solution par la méthode de Kuzdzal-Savoie modifiée [3], l'acide pélargonique était employé comme étalon interne.

Après séparation des acides gras libres, le procédé de la chromatographie en phase gazeuse était employé, les savons ayant été traités préalablement d'après la méthode décrite par Ross et al. [11].

\section{B) CONDITION DE LA SÉPARATION CHROMATOGRAPHIQUE}

Un appareil de Carbo Erba, modèle $C$, type AJD/f. Détection à ionisation de flamme. Colonne de verre, $2 \mathrm{~m}$ de longueur, diamètre interne $3 \mathrm{~mm}$, charge -10 p. 100 de succinate de diéthyle (DEGS), additionné de 2 p. 100 de $\mathrm{H}_{3} \mathrm{PO}_{4}$ sur chromosorbic $\mathrm{W}$ acid washed $80 / 100$ mesh. Gaz vecteur $N_{2}$, pression à la sortie de la colonne 1,2 atm, débit $35 \mathrm{ml} / \mathrm{mn}$.

L'hydrogène, à raison de $30 \mathrm{ml} / \mathrm{mn}$, provenant du générateur d'hydrogène Aérograph, ainsi que l'air, à raison de $600 \mathrm{ml} / \mathrm{mn}$, étaient amenés au brûleur. La distribution était effectuée en cycle isothermique à $165^{\circ} \mathrm{C}$. L'identification des pics et le calibrage des signaux 
de détecteur étaient effectués à la base du mélange témoin des acides gras libres de $\mathrm{C}_{2}$ à $\mathrm{C}_{10}$.

Des signaux de détecteur étaient enregistrés à l'aide d'un compensateur à l'enregistreur, à l'échelle $2 \mathrm{mV}$, le temps écoulé de toute l'échelle $2 \mathrm{~s}$, la vitesse d'avancement du ruban $600 \mathrm{~mm} / \mathrm{h}$.

Les résultats étaient calculés à partir de la masse des pics, préalablement redessinés sur le papier-calque technique et découpés.

\section{Résultats}

Les résultats qui ont été rassemblés dans les tableaux 1 , 2 et 3 indiquent que les suspensions de bactéries lactiques étudiées, ainsi que celles des moisissures, possédaient l'aptitude à produire des acides gras à partir des acides aminés qui étaient formés au cours de l'hydrolyse de la caséine par les organismes en question. Toutes les souches de bactéries étudiées ont montré une aptitude plus élevée à former des acides gras à $\mathrm{pH} 6,5$ à partir de substrat. $\mathrm{Si}$ dans le substrat qui a été incubé à pH 5,6 la quantité des acides gras produits variait entre $83,5-108,8 \mathrm{mg}$ pour $100 \mathrm{~g}$ de caséine, elle s'élevait à $329,5-1621,2 \mathrm{mg}$ pour $100 \mathrm{~g}$ de caséine à $\mathrm{pH}$ 6,5. C'était la souche de Str. diacetilactis qui montrait l'aptitude la plus élevée à produire les acides en question, tandis que celle de Str. Lactis se caractérisait par la composition quantitative des acides libres plus convenable. Cette souche produisait principalement des acides acétique et propionique, ainsi que très peu d'acide butyrique et des quantités insignifiantes d'acides à plus de 4 atomes de carbone. Bien que Str. diacetilactis produisît plus de $\mathrm{C}_{2}$ et de $\mathrm{C}_{3}$, et des quantités d'acide butyrique approchant celles qui étaient produites par Str. lactis il produisait pourtant beaucoup d'acide isovalérique $(638 \mathrm{mg}$ en moyenne) et des quantités importantes d'acides à chaîne carbonique allongée, environ un tiers de toute la quantité d'acides gras libres produits. Str. cremoris synthétisait aussi de grandes quantités de $C_{2}$ (96 mg en moyenne), des quantités très élevées de $C_{3}(340 \mathrm{mg})$, et cependant, des quantités extrêmement élevées de $C_{*}(223 \mathrm{mg})$, dix fois à peu près plus que celles des autres souches étudiées, semblent indésirables. Néanmoins, la même souche ne montrait pas une tendance semblable, lorsqu'elle était incubée à $\mathrm{pH} 5,5$. Il est intéressant d'observer que la culture mixte des trois souches bactériennes étudiées produisait moins d'acides gras libres que les mêmes souches incubées séparément. Les moisissures étudiées produisaient sensiblement moins d'acides gras libres que ne le faisait la biomasse de germes des bactéries lactiques. Toutes les sortes des germes analysés (tab. 2) produisaient les quantités les plus élevées d'acide valérique, tendance qui se manifestait déjà après $24 \mathrm{~h}$ d'incubation. C'était la souche de $P$. roqueforti qui produisait le moins de cet acide $(20 \mathrm{mg})$, et c'était Oidium lactis qui en produisait le plus. A son tour, l'acide propionique était le second, dont de grandes quantités étaient pro- 
TABLEAU 1

Quantités d'acides gras libres produits au cours de la décomposition de la caséine par des bactéries :

Str. lactis, Str. cremoris, Str. diacetilactis et leur culture mixte (moyennes de 2 essais) en $\mathrm{mg} / 100 \mathrm{~g}$ de caséine

et pourcentage des acides divers

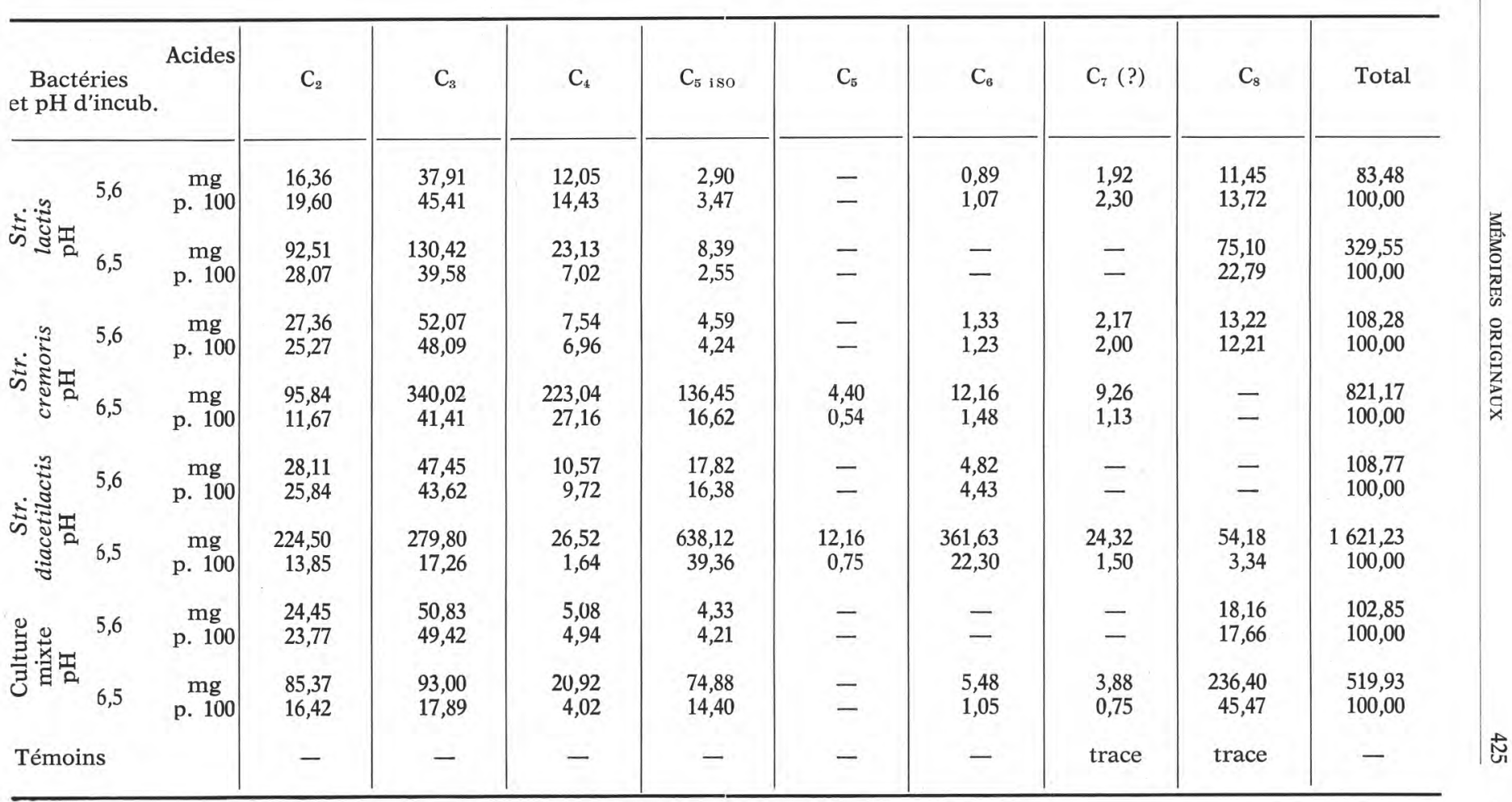


duites, et surtout après $5 \mathrm{j}$ d'incubation. P. roqueforti et Zygorhyntus meelleri manifestaient une aptitude assez élevée à produire de l'acide acétique, tandis que $O$. lactis et Rhizopus oligosporus n'en produisaient que des quantités minimes aux premières heures d'incubation. L'acide butyrique n'était produit que par Rhizopus oligosporus. Cette espèce produisait aussi des quantités plus élevées d'acides supérieures à l'acide isovalérianique que ne le faisaient toutes les autres espèces de moisissures.

Au cours de la formation des acides gras volatils, l'activité des enzymes qu'on obtenait à partir de la moisissure Zygorhyntus était bien plus élevée que celle de la moisissure elle-même qui se développait sur le même milieu [3]. Des préparations enzymatiques intracellulaires synthétisaient plus de $C_{3}$ que des préparations extracellulaires, mais elles produisaient aussi certaines quantité de $C_{*}$ et relativement beaucoup d'acides supérieurs à $C_{5}$. Les deux préparations produisaient un excès d'acide isovalérique et c'était surtout le cas de la préparation extracellulaire après incubation de $5 \mathrm{j}-2150 \mathrm{mg}$ c'est-à-dire 80 p. 100 de tous les acides gras libres produits.

En cas de la préparation intracellulaire, la proportion de l'acide $\mathrm{C}_{5}$-iso aboutissait à 36 p. 100 . Ce pourcentage élevé de l'acide isovalérique a été constaté aussi pour la même souche de moisissure incubée dans la solution de caséine -75 p. 100 après $5 \mathrm{j}$ d'incubation et 45 p. 100 après 24 h (tab. 3).

\section{Discussion}

Nakae et Elliot [5] rapportent que 80 p. 100 des acides libres totaux qui étaient produits par des bactéries de la fermentation lactique se composaient des acides : acétique, propionique et isovalérique. Dans nos observations, après $5 \mathrm{j}$ d'incubation, la proportion de ces acides se maintenait, pour des souches particulières, au niveau de 70 p. 100 , sans surpasser 50 p. 100 au cas de la culture mixte des souches. Une proportion bien plus élevée de ces acides était constatée dans le substrat de caséine incubé pendant $5 \mathrm{j}$ avec des sortes de moisissures diverses ( $P$. roqueforti -87 p. 100 , O. lactis $-99,8$ p. 100 , $R$. oligosporus -96 p. 100 et $Z$. meelleri -94 p. 100). Dans le substrat de caséine incubé avec la préparation enzymatique intracellulaire de Z. meelleri, les acides libres $C_{2}, C_{3}$ et $C_{5}$-iso constituaient 73 p. 100 , et ils aboutissaient à 97 p. 100 dans le substrat de caséine incubé avec la préparation extracellulaire. Outre cela, au contraire des bactéries de la fermentation lactique, des moisissures, ainsi que des préparations enzymatiques de moisissures, ne produisaient point d'acide butyrique. On sait, que de grandes quantités de cet acide sont indésirables dans les fromages, parce qu'elles en réduisent sensiblement la qualité. Cette caractéristique des moisissures et des préparations de moisissures est donc extrêmement avantageuse sous ce rapport. Il paraît pourtant bien peu satisfaisant d'observer que les moisissures et les préparations enzymatiques étudiées produisaient de trop 


\section{TABLEAU 2}

Quantités d'acides gras libres produits au cours de la décomposition de la caséine par des moisissures :

P. roqueforti, Oidium lactis, Rhizopus oligosporus et Zygorhyntus meelleri (moyennes de 2 essais) en mg/100 g de caséine et pourcentage des acides divers

\begin{tabular}{|c|c|c|c|c|c|c|c|c|c|c|c|}
\hline \multicolumn{2}{|c|}{ Moisissures } & Acides & $\mathrm{C}_{2}$ & $\mathrm{C}_{3}$ & $\mathrm{C}_{4}$ & $C_{5}$ iso & $\mathrm{C}_{6}$ & $\mathrm{C}_{i}$ (?) & $\mathrm{C}_{8}$ & $\mathrm{C}_{10}$ & Total \\
\hline \multirow{2}{*}{ 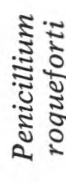 } & 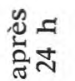 & $\begin{array}{c}\mathrm{mg} \\
\text { p. } 100\end{array}$ & $\begin{array}{r}2,46 \\
35,39\end{array}$ & $\begin{array}{r}0,74 \\
10,64\end{array}$ & $=$ & $\begin{array}{r}2,97 \\
42,74\end{array}$ & $\overline{-}$ & $=$ & $\begin{array}{r}0,78 \\
11,23\end{array}$ & $\overline{-}$ & $\begin{array}{r}6,95 \\
100,00\end{array}$ \\
\hline & 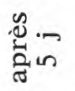 & $\begin{array}{c}\mathrm{mg} \\
\text { p. } 100\end{array}$ & $\begin{array}{l}8,78 \\
9,50\end{array}$ & $\begin{array}{l}61,40 \\
66,41\end{array}$ & - & $\begin{array}{l}19,70 \\
21,31\end{array}$ & $\begin{array}{l}2,57 \\
2,78\end{array}$ & - & $\overline{-}$ & - & $\begin{array}{r}92,45 \\
100,00\end{array}$ \\
\hline \multirow{2}{*}{$\tilde{z}: \tilde{z}$} & 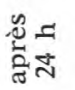 & $\begin{array}{c}\mathrm{mg} \\
\text { p. } 100\end{array}$ & $\begin{array}{r}0,79 \\
25,16\end{array}$ & $\begin{array}{r}0,49 \\
15,61\end{array}$ & - & $\begin{array}{r}0,76 \\
24,20\end{array}$ & - & $=$ & $\begin{array}{r}1,10 \\
35,03\end{array}$ & - & $\begin{array}{r}3,14 \\
100,00\end{array}$ \\
\hline & 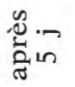 & $\begin{array}{c}\text { mg } \\
\text { p. } 100\end{array}$ & - & $\begin{array}{r}266,50 \\
30,75\end{array}$ & - & $\begin{array}{r}599,20 \\
69,14\end{array}$ & $\begin{array}{l}0,88 \\
0,10\end{array}$ & $\overline{-}$ & - & - & $\begin{array}{l}866,58 \\
100,00\end{array}$ \\
\hline \multirow{2}{*}{ 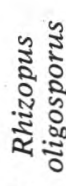 } & 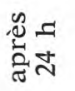 & $\begin{array}{c}\mathrm{mg} \\
\text { p. } 100\end{array}$ & $\begin{array}{l}1,10 \\
3,73\end{array}$ & $\begin{array}{l}0,52 \\
1,76\end{array}$ & $\begin{array}{r}7,92 \\
26,82\end{array}$ & $\begin{array}{l}2,41 \\
8,16\end{array}$ & $\begin{array}{r}7,53 \\
25,50\end{array}$ & $\begin{array}{l}2,52 \\
8,53\end{array}$ & $\begin{array}{r}3,89 \\
13,17\end{array}$ & $\begin{array}{r}3,64 \\
12,32\end{array}$ & $\begin{array}{r}29,53 \\
100,00\end{array}$ \\
\hline & 蒂. & $\begin{array}{c}\mathrm{mg} \\
\text { p. } 100\end{array}$ & - & $\begin{array}{l}45,84 \\
30,39\end{array}$ & - & $\begin{array}{l}99,10 \\
65,70\end{array}$ & $\begin{array}{l}1,16 \\
0,77\end{array}$ & - & $\begin{array}{l}1,80 \\
1,20\end{array}$ & $\begin{array}{l}2,93 \\
1,94\end{array}$ & $\begin{array}{l}150,83 \\
100,00\end{array}$ \\
\hline \multirow{2}{*}{ 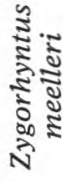 } & 导止 & $\begin{array}{c}\mathrm{mg} \\
\text { p. } 100\end{array}$ & $\begin{array}{l}0,69 \\
5,26\end{array}$ & $\begin{array}{r}2,77 \\
21,13\end{array}$ & $\overline{-}$ & $\begin{array}{r}5,84 \\
44,55\end{array}$ & $\begin{array}{l}0,30 \\
2,29\end{array}$ & $\begin{array}{l}0,38 \\
2,90\end{array}$ & $\begin{array}{r}1,87 \\
14,26\end{array}$ & $\begin{array}{l}1,26 \\
3,61\end{array}$ & $\begin{array}{r}13,11 \\
100,00\end{array}$ \\
\hline & 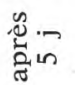 & $\begin{array}{c}\text { mg } \\
\text { p. } 100\end{array}$ & $\begin{array}{l}2,56 \\
3,67\end{array}$ & $\begin{array}{l}14,08 \\
20,16\end{array}$ & - & $\begin{array}{l}48,90 \\
70,00\end{array}$ & $\begin{array}{l}0,55 \\
0,79\end{array}$ & - & $\begin{array}{l}1,54 \\
2,21\end{array}$ & $\begin{array}{l}2,20 \\
3,15\end{array}$ & $\begin{array}{r}69,83 \\
100,00\end{array}$ \\
\hline \multicolumn{2}{|c|}{ Témoin } & & $\begin{array}{r}0,34 \\
11,97\end{array}$ & $\begin{array}{l}0,01 \\
0,35\end{array}$ & - & $\begin{array}{l}0,01 \\
0,35\end{array}$ & $\begin{array}{l}0,04 \\
1,41\end{array}$ & $\begin{array}{l}0,24 \\
8,45\end{array}$ & $\begin{array}{r}1,21 \\
42,61\end{array}$ & $\begin{array}{r}0,99 \\
34,84\end{array}$ & $\begin{array}{r}2,84 \\
100,00\end{array}$ \\
\hline
\end{tabular}




\section{TABLEAU 3}

Quantités d'acides gras libres produits au cours de la décomposition de la caséine par les enzymes extracellulaires et intracellulaires de la moisissure Zygorhyntus meelleri (moyennes de 2 essais) en $\mathrm{mg} / 100 \mathrm{~g}$ de caséine et pourcentage des acides divers

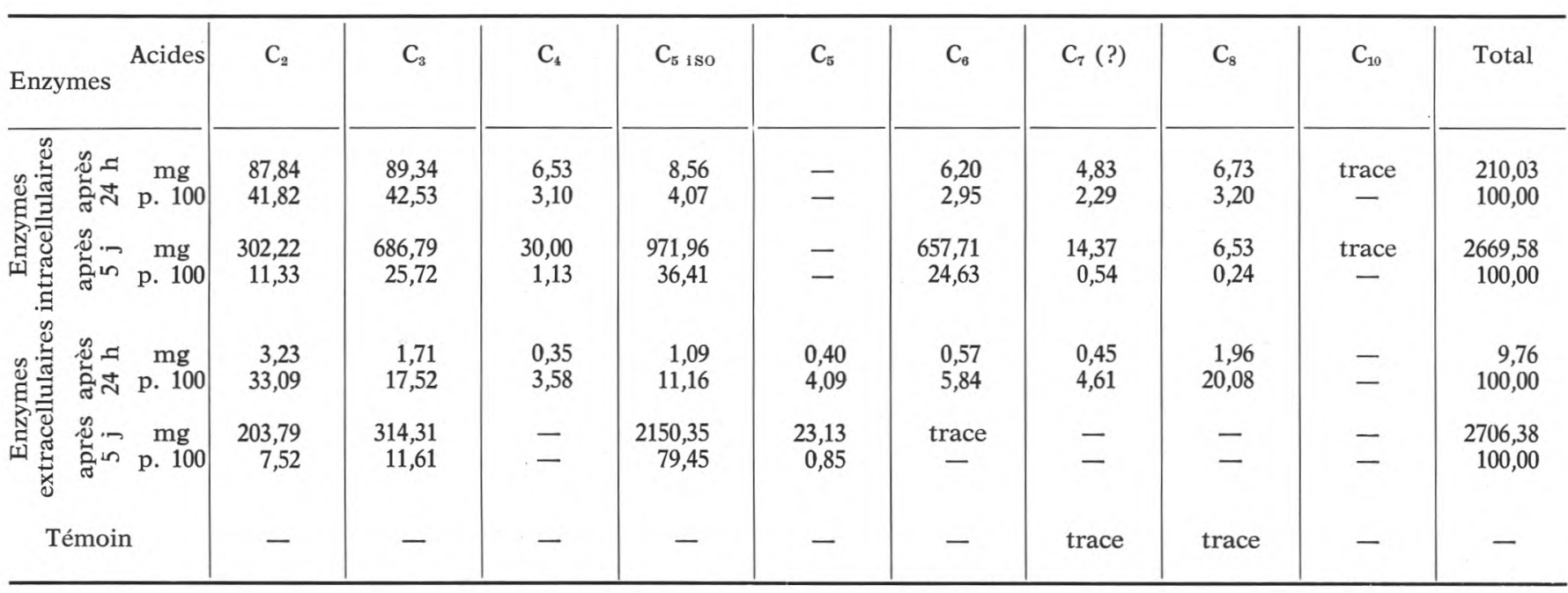


grandes quantités d'acide isovalérianique. Zegarska [13] a constaté qu'il existait un rapport entre la teneur en isoacides et les caractéristiques défectueuses de goût et d'odeur des fromages. Ayant en vue l'absence de production d'acide butyrique et le pouvoir limité de produire l'acide isovalérique, c'est $P$. roqueforti qui nous paraît la sorte la plus convenable des moisissures que nous avons étudiéc. Nakae et Elliot [5] ont rapporté que la présence d'acides gras libres supérieurs à l'acide caproïque n'était pas liée à la décomposition des protéines, mais qu'elle pouvait provenir de micro-organismes qui subissaient l'autolyse au cours de l'incubation. En considérant les traces de ces acides du substrat de caséine qui était incubé avec la préparation enzymatique extracellulaire, et les teneurs très élevées du substrat incubé avec la préparation intracellulaire, il apparaît qu'en notre cas les moisissures étaient une source d'acides gras contenant plus de 5 atomes de carbone.

\section{R és u m é}

On a étudié l'aptitude de bactéries de la fermentation lactique. de moisissures et de préparations enzymatiques intracellulaires et extracellulaires à produire des acides gras libres. Les micro-organismes et les préparations enzymatiques étudiées possédaient l'aptitude à produire des acides gras libres à partir du substrat de caséine à $\mathrm{pH} 6,5$ et 5,5. Les moisissures et la préparation extracellulaire de moisissures produisaient beaucoup d'acide valérique, sans produire d'acide butyrique. Les souches de bactéries de la fermentation lactique étudiées produisaient l'acide butyrique. Str. cremoris 319 montrait de hautes possibilités sous ce rapport. Ayant en vue l'utilisation des enzymes de moisissures dans l'affinage des fromages, il nous paraît que $P$. roqueforti est la sorte de moisissure la plus convenable de celles que nous avons étudiées. Cette moisissure ne produit point d'acide butyrique et seulement des quantités limitées d'acide isovalérique ; par contre, elle produisait de grandes quantités d'acide propionique et acétique.

\section{$\mathrm{S}$ u $\mathrm{m}$ m a r y}

\section{Production of Free Fatty Acids by Lactic Fermentation Bacteria and Moulds on Casein Medium}

Lactic fermentation bacteria, moulds as well as intracellular and intracellular mould enzyme preparations were investigated on their ability of producing free fatty acids. Microorganisms and enzyme preparations studied were found to be able to produce free fatty acids from casein substrate of $\mathrm{pH}$ values 6,5 and 5,5. Moulds and extracellular enzyme preparations produced considerable amounts of isovaleric acid but they failed to produce butyric acid. All strains studied of lactic acid bacteria produced butyric acid, and Str. cremoris showed high abilities for that matter. In view of utilizing 
mould enzymes for cheese maturation. $P$. roqueforti appeared to be most suitable of all mould studied. It produced no butyric acid and only limited amounts of isovaleric one while producing considerable amounts of propionic and acetic acids at the same time.

\section{Bibliographie}

[1] Efthymion (C.) (1967). - Major Free Fatty Acids of Feta Cheese. J. Dairy Sci., 50, p. 20.

[2] HaRPER (W. J.) and Long (J. E.) (1956). - Italian Cheese Ripening. IV. Varieus Free Amino and Fatty Acids in Commercial Provolone Cheese. J. Dairy Sci., 39, p. 129.

[3] Kuzdzal-Savoie (S.) et Kuzdzal (W.) (1967). - Les acides gras libres du fromage. Le Lait, $\mathrm{n}^{\circ} 461-462$, p. 9-23.

[4] Nakae (T.) and Elliot (J. A.) (1965). - Volatile Fatty Acids Produced by some Lactic Acid Bacteria. Factors Influencing Production of Volatile Fatty acids from Casein Hydrolyzate. I. Dairy Sci., 48, p. 287.

[5] NAKAE (T.) and Elliot (J.A.) (1965). - Production of Volatile Fatty Acids by some Lactic Acid Bacteria Selective Formation of Volatile Fatty Acids by Degradation of Amino Acids. J. Dairy Sci., 48, p. 293.

[6] Niкiт Yоsніока and Анікок (1966). - Proteolitic and Lipolytic Activities of Penicillium Roqueforti Isolated from Blue Cheese. XVII Int. Dairy Congr., t.D., p. 531-537.

[7] Patton (S.) (1964). - Volatile Acids of Swiss Cheese. J. Dairy Sci., 47, p. 817.

[8] Patton (S.) (1963). - Volatile Acids and the Aroma of Cheddar Cheese. J. Dairy Sci., 46, p. 856.

[9] Poznanski (S.), Kowalewska (J.) and Jaworski (J.) (1968). - Free Fatty Acids in Ripe Cheeses of Different Qualities. Austral. J. Dairy Techn., 23 , p. 126.

[10] Ribadeau-Dumas (B.), Maubois (J. L.), Mocouot (G.) et Garnier (J.) (1964). Etude de la constitution de la caséine de vache par chromatographie sur colonnes de diéthylaminoéthylcellulose en milieu urée. Biochim. Biophys. Acta, 8, p. 49.

[11] Roos (J. B.), Versnel (A.) und Wermüller (A.) (1963). - Die Gaschromatographishe Bestimmung der niederen Fettsairen von Milchfett un Daren Anwedung zum Nachweis von Frendsfetten. Kieler Milchwirt. Farshung, 15 , p. 515

[12] Rymaszewski (J.), Poznanski (S.) et Maginska (Cz). - Utilisation de la biomasse des bactéries de la fermentation lactique pour la fabrication des fromages. Le Lait, 1971, $\mathrm{n}^{\circ}$ 501/2, 23-24.

[13] ZeGARSKA (Z) (1969). - Charakterystyka wolnych kwasôw tluszczowych powstajacych podczas dojrzewania serôw. Praca dysertacyjna, WSR Olsztyn .

[14] Valles (E.) et Mocouot (G.) (1968). - Préparation de suspensions concentrées et congelées de bactéries lactiques thermophiles destinées à la fromagerie, Le Lait, $\mathrm{n}^{\circ} 479-480$, p. 631.

Reçu pour publication en janvier 1971. 